\title{
O PATRIMÔNIO É UMA APOSTA: O CASSINO DA URCA E A INOVAÇÃO INSTITUCIONAL EM ESPAÇOS DE ARTE E DO ENTRETENIMENTO NO BRASIL*
}

\author{
El património és um juego: él Casino da Urca y la inovaión em los espacios del arte y del entretenimiento em \\ Brasil
}

The bet of patrimony - Institutional innovation of art and entertainment spaces in Brazil: the case of Casino da Urca

Liliana Fiuza Magalhães

Universidade Federal do Rio de Janeiro (UFRJ), Brasil

lilianafiuzamagalhaes@gmail.com

\author{
DOI: https://doi.org/10.18472/cvt.20n2.2020.1832 \\ Redalyc: http://www.redalyc.org/articulo.oa? \\ $\mathrm{id}=115464354007$
}

Recepción: 18 Junio 2020

Aprobación: 20 Agosto 2020

\section{Resumo:}

O artigo apresenta uma análise sobre a configuração de patrimônio imaterial de lugar sob a perspectiva de Peter Hall (1998) quanto à cultura e o padrão civilizatório urbano. Discute o tema a partir de uma reflexão sobre como e porque o Cassino da Urca se configurou um ícone da cultura da cidade do Rio de Janeiro, e do espírito do seu tempo, e explora o inédito reconhecimento da cidade como paisagem cultural urbana patrimônio mundial da humanidade pela UNESCO. Ao apresentar lideranças carismáticas fundamentais no desenvolvimento daquela que foi considerada a melhor casa de espetáculo da América Latina, destaca seus papéis e suas apostas nas relações de diálogo e enraizamento com seu território (Zaoual, 2006) como condições favoráveis para que as potencialidades culturais de uma época se efetivem num lugar. A investigação busca contribuir com os estudos da gestão da inovação institucional em espaços da arte e entretenimento na sociedade hoje.

Palavras-Chave: Patrimônio, Protagonismo situado, Gestão cultural.

\section{Abstract:}

The article presents an analysis regarding how a site is configured as an intangible heritage asset considering the perspective of Peter Hall (1998) concerning the culture and the urban civilizing pattern. Discusses such subjects reflecting how and why "Casino da Urca " managed to become an icon of the culture of the city of Rio de Janeiro, capturing the spirit of its time. Further, explores the unprecedented recognition of the city as an urban cultural landscape world heritage site of humanity by UNESCO. Presenting charismatic leaders who were fundamental in the development of that which were back then considered the best venue in Latin America, the article moves forward highlighting their roles and their bets, both supported by dialogical and grass-rooted relations among its territory agents (Zaoual, 2006) as a favorable condition to succeed a cultural enterprise and enable culture potentials in terms of development and innovation. The investigation aims to contribute with contemporary studies on management and institutional innovation of the art and entertainment spaces.

KEYWORDS: Heritage, Situated protagonism, Cultural management.

\section{RESUMEN:}

El artículo presenta un análisis de la configuración del patrimonio inmaterial del lugar desde la perspectiva de Peter Hall (1998) con respecto a la cultura y el patrón de civilización urbana. Discute el tema a partir de una reflexión sobre cómo y por qué Cassino da Urca se convirtió en un ícono de la cultura de la ciudad de Río de Janeiro y del espíritu de su tiempo, y explora el reconocimiento sin precedentes de la ciudad como un paisaje cultural urbano patrimonio mundial de la humanidad por la UNESCO. Al presentar líderes carismáticos que son fundamentales en el desarrollo de lo que se consideró el mejor lugar en América Latina, destaca sus roles y sus apuestas sobre las relaciones de diálogo y arraigo con su territorio (Zaoual, 2006) como condiciones favorables para el potencial cultural de un época tiene lugar en un solo lugar. La investigación busca contribuir a los estudios organizacionales de innovación institucional en espacios de arte y entretenimiento en la sociedad actual.

Palabras clave: Património, Protagonismo situado, Gestión cultural. 


\section{INTRODUÇÃO}

A cidade do Rio de Janeiro é hoje reconhecida pela Organização das Nações Unidas para a Educação, a Ciência e a Cultura - UNESCO como Patrimônio Mundial da Humanidade pela sua paisagem cultural urbana. A cidade ganha o título inédito em 2012 a partir da complexa integração impositiva entre a ação da natureza e do homem, tendo como uma das suas características a relação da geografia e da cultura e suas interferências mútuas na configuração urbana.

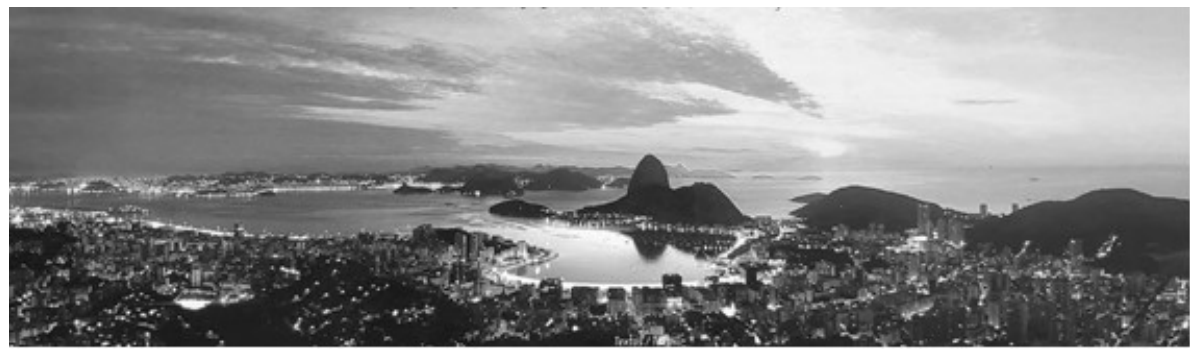

FIGURA 1.

Vista Panorâmica do Rio de Janeiro.

Fonte: Helmut Batista, Rio de Janeiro 360, 2002.

Nesse aspecto, apontamos o bairro da Urca como um exemplo e representação da formação do Rio de Janeiro. Marco inicial do surgimento da cidade, o lugar teve vários momentos na sua configuração urbana, sendo o último e decisivo ocorrido em 1918 mais de 300 anos após a primeira ocupação. Na esteira do impulso empreendedor das grandes reformas urbanísticas de 1922 a Urca foi planejada e construída quase que totalmente sobre o mar, com ares da modernidade e do bem-viver e termina por configurar sua atual integração com a cidade (Aizen,1990). Uma das contrapartidas no contrato entre a prefeitura e os empreendedores, responsáveis pelo aterramento e exploração imobiliária do bairro, foi a construção de um equipamento de lazer e turismo que trouxesse para o lugar um ponto singular de convivência cultural e integração social com a cidade.
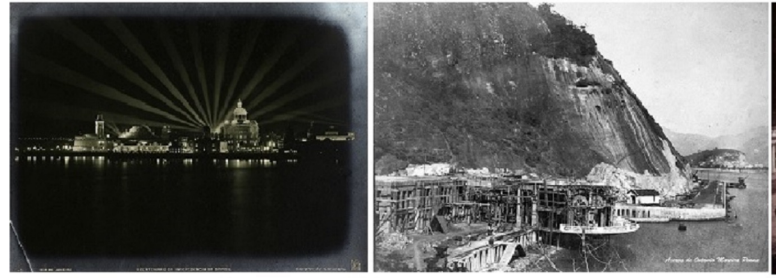

FIGURA 2

Painel Rio de Janeiro, Urca, início dos anos 1920

Fonte: Thiele \& Kollien/Acervo Instituto Moreira Salles, Exposição Internacional do Centenário da Independência,1922. Augusto Malta/ Acervo Família Otávio Moreira Penna, Construção Hotel Balneário da Urca. Hotel Balneário 1923/24. Rio de Janeiro.

O equipamento protagonizou um papel inovador na formação da cultura carioca e brasileira pelos diferentes empreendimentos que marcaram seus momentos-chave: o Hotel Balneário que operou entre 1922 e 1932 como instância de lazer e turismo, relacionado à introdução do hábito do banho de mar; o Cassino da Urca, que funcionou entre 1933 e 1946, período em que houve a legalização do jogo e que marca o surgimento da emblemática casa de espetáculos e por fim, o lugar abrigou os estúdios da primeira emissora de televisão do país a TV Tupi, entre 1951 e 1980. Embora os três momentos que marcaram a atuação do equipamento no período de quase sessenta anos guardem funções históricas próprias, foi o Cassino da Urca que trouxe ao bairro a marca de um lugar da cidade que a definia como maravilhosa e a projetava internacionalmente. Até hoje o local é conhecido e nomeado como Cassino da Urca e o reconhecimento do 
prédio como patrimônio histórico vem de um processo histórico de significativa apropriação institucional da memória coletiva. Em 1976 ocorre o tombamento paisagístico do bairro em nível federal e a municipalidade determina o tombamento definitivo dos bens culturais delimitando a área de entorno e o prédio em 1988. Uma lei municipal o torna de interesse histórico e cultural em 2009, e em 2018, o prefeito da cidade do Rio de Janeiro, reafirma o valor histórico e cultural do imóvel pelo poder executivo ao tombar o antigo Cassino da Urca com o objetivo de assegurar o uso do lugar de forma compatível com o seu valor histórico cultural. Baseado no sistema de normas e proteção ao patrimônio cultural no país, bens que carregam reconhecimento de patrimônio cultural com caracterização de lugar representam o prédio e o que nele ocorreu (ou ocorre) e onde as dimensões do material e do imaterial se relacionam e se articulam (Fonseca, 2017). Por esse motivo, nos interessa abordar a dimensão imaterial do Cassino da Urca por meio de um olhar sobre a forma relacional criada pelas pessoas que apostaram e desenvolveram aquela que chegou a ser considerada, no período, como a melhor casa de espetáculo da América Latina e que impactou na mudança dos rumos da vida artística e cultural brasileira. Este artigo se justifica pela intenção de contribuir com os estudos da gestão do patrimônio cultural hoje com especial interesse no entendimento contemporâneo de cultura como recurso (Yúdice, 2004) de natureza intangível e como um bem imaterial no âmbito de ação da sociedade e seus organismos público, privado e da comunidade organizada. Reconhecer a cultura e sua diversidade de expressões como recursos implica na ideia de que a gestão desses recursos, tem no protagonismo das pessoas uma questão chave se considerarmos suas capacidades de aposta situada nos seus territórios. Nesse quadro, nos parece oportuno compreender esses equipamentos culturais como institucionalidades situadas, cuja importância para a sociedade esteja enraizada nas relações de aposta no diálogo, intercâmbio, aprendizado e valoração recíproca que mantenham com seus territórios (Zaoual, 2006). A análise que se segue visa colaborar para atualizar essa compreensão nos contextos da gestão cultural e a ela associados a partir da perspectiva do protagonismo de profissionais criativos, líderes carismáticos, gênios criadores que na visão de Peter Hall (1998), em seus estudos sobre a cultura e o padrão civilizatório urbano, são apontados como agentes que inserem inovações significativas e transformadoras e promovem uma vida cultural gloriosa em uma determinada época tornando-a culturalmente influente. Com a análise do que ocorreu no Cassino da Urca, pretendemos nesse artigo responder ao questionamento: Como o protagonismo situado propicia condições mais favoráveis para que as potencialidades culturais de uma época se efetivem num lugar?

\section{A PESQUisa}

Por meio de uma pesquisa de estudo de caso, buscamos delinear os limites entre contextos e fenômenos ocorridos durante o funcionamento do Cassino da Urca. Todo o trabalho foi amparado por um levantamento arquivístico documental, iconográfico e hemerográfico ${ }^{[1]}$, associado a uma literatura ensaística, histórica e filosófica.

A leitura da pesquisa iconográfica revelou um significativo repertório de fatos e imagens que representa a realidade e efemérides marcantes na atuação do Cassino da Urca e teve como principal fonte uma vasta documentação identificada em incursão nas coleções de periódicos da Biblioteca Nacional. Com um recorte de busca no período de 1930 a 1946, identificou-se uma concentração de publicações de matérias, notícias, reportagens, notas, anúncio e encartes sobre o Cassino da Urca em periódicos como; a Revista O Cruzeiro e nos jornais; A Noite, O Jornal, A Manhã, Gazeta de Notícias, Jornal do Brasil e O Imparcial. Neles se destacaram as presenças de cinco personagens que por meio do carisma de suas figuras ou por meio das suas trajetórias e do resultado dos seus trabalhos impactaram na configuração do que se tornou o Cassino da Urca e por isso passaram a ser alvo do nosso interesse de análise. Relevante também foi o acesso ao acervo da coleção iconográfica do Instituto Moreira Salles - IMS, das quais foram selecionadas imagens que tratam da cobertura fotográfica do que ocorria no Cassino da Urca. O Acervo de imagens ajudou a construir a narrativa ao se somar com os anúncios, notas e matérias jornalísticas do acervo, também do IMS, de publicações por meio da 
Revista de grande circulação na época; Careta, Para Todos e Ilustração Brasileira. Enquanto o anunciado na introdução desse artigo trouxe pontos de embasamento e formulação da questão chave, a argumentação que se segue se baseia nas biografias dos personagens identificados como representantes simbólicos da construção do lugar. Já o caráter da análise se deu sem se estabelecer a priori as referências teóricas, elas foram surgindo e assim caracterizando o processo do estudo como qualitativo e de orientação pós-estruturalista.

\section{O CENÁRIO POLÍTICO SOCIAL E A EMERGENTE INDÚSTRIA CULTURAL}

Para buscar compreender como o Cassino da Urca se desenvolveu e o lugar se tornou um polo do entretenimento da vida social e artística no período entre 1933 e 1946 no Rio de Janeiro, se faz necessário um olhar de como se apresenta a dinâmica cultural em seus variados modos e significados (Coelho, 2008) no contexto político, econômico, social e artístico em que nascem os cassinos no Brasil. A Revolução de 1930 termina com a república das oligarquias e leva à presidência da república o político gaúcho Getúlio Vargas e em 1934 é promulgada uma nova Constituição com mudanças progressistas. No planejamento e execução econômica social ocorrem ações como: a legalização do jogo a partir de uma política pública de incentivo ao turismo (1933) e em 1935 é instituída uma lei que obriga os cassinos a contratar artistas nacionais em número equivalente aos estrangeiros que até então eram as principais atrações dos cassinos. Já em 1931 Getúlio regulamenta a abertura de estações de rádio no país inteiro e estimula a instalação de serviços de autofalante nas praças das cidades que não tivessem uma emissora e assim abre passagem para música brasileira (Castro, 2005). Getúlio fica historicamente identificado como o primeiro presidente a compreender o papel da cultura no país e a fazer uso político disso e na segunda fase de governo, caracterizada como Estado Novo, a ditadura criou também o departamento de Imprensa e Propaganda para censurar e controlar manifestações opostas ao governo. No período de 1920 a 40 o Rio de Janeiro vivia o frenesi da formação de uma indústria cultural que se alimentava dos teatros, das rádios e do cinema tendo tanto as gravadoras quanto as revistas e jornais como meios promotores e estimuladores do consumo dessa então nova cadeia produtiva criativa. No cinema, entre 1925 e 1930, surgiu uma espécie de Broadway carioca com palácios cinematográficos no centro da capital federal, e se viu nascer o Império, o Glória, o Capitólio e o Odeon. (Castro, 2005). Nesse período, o teatro de revista se tornou um gênero consagrado com as comédias de costumes com música, dança e quadros humorísticos com o dom da crítica à vida social com dançarinas em números musicais acompanhados por grandes orquestras. O rádio nasce com duas emissoras na capital federal; a Rádio Sociedade do Rio de Janeiro e a Rádio Clube do Brasil em 1923. Já a indústria fonográfica brasileira que se inicia com Casa Edison (primeira gravadora da América Latina) representante da gravadora alemã Odeon, adere a gravação elétrica em 1927. A tecnologia também chega às rádios, surgem mais estações como a Mayrink Veiga, a Philips e a Educadora e as programações passam a ter um perfil de grêmio litero-musical e a música brasileira tem no samba sua maior representação a partir dos anos 1930. A época de ouro da música brasileira começa a ser marcada a partir de 1932 no rádio, no disco, no teatro e no cinema e é alavancada com o Decreto-Lei do Governo Federal que autoriza a propaganda no rádio; as emissoras de rádio se profissionalizam, criam programações, contratam os artistas e apresentam anúncios pagos pelo comércio. Em 1935 a emergente indústria cultural no Rio de Janeiro já girava em torno de "noventa e cinco cinemas, oito circos, quatro cabarés e sete teatros. [...] e eram registrados só no Distrito federal 515 artistas integrados as artes cênicas, espetáculos musicais, circenses e cabarés." (Santucci,2005, p.134).

No Brasil, essa indústria cultural, que já se encontrava pulsando no início dos anos 30, é potencializada com legalização do jogo quando surgem com os cassinos as condições para consolidação um novo modo de entretenimento; o do espetáculo. Porém, é nas ideias de Guy Debord (2007), precursor da análise crítica da moderna sociedade do consumo e sua teoria crítica acerca da sociedade do espetáculo, que se revela o contexto de uma indústria cultural que surgiu naqueles anos 30-40 e que teve o Cassino como um elo precursor da cultura do espetáculo no Brasil. Ao considerar que o espetáculo não é um conjunto de imagens, mas uma 
relação social entre pessoas, mediada por imagens (Debord, 2007), o que se apresenta a seguir no estudo de caso do Cassino da Urca, pode ser visto como um fenômeno que - a luz da relação social de seus atores em um protagonismo situado (Zaoual, 2006) - revelou novos códigos culturais que impulsionam para mudanças no modo e na escala do fazer entretenimento cultural do país.

\section{O Cassino da Urca na construção da paisagem Cultural carioca}

Ao longo dos anos, a metrópole tropical do Rio de Janeiro foi sendo edificada não só como num reflexo visual impactante da natureza, mas também como seu retrato por meio dos aspectos sócios culturais históricos e urbanísticos. O título da UNESCO de Paisagem Cultural Urbana que declara a cidade como Patrimônio Mundial, é o primeiro a ser dado a uma área urbana no mundo por reconhecer o valor universal da originalidade da geografia e pelos valores universais excepcionais que marcam a paisagem cultural da cidade. Esses valores universais excepcionais foram defendidos no dossiê de candidatura do Rio a patrimônio mundial, em 2011, e um entre os três critérios estabelecidos é por "representar uma obra prima de um gênio criativo humano" (UNESCO, 1972 apud IPHAN et al., 2011, pp. 17-21). O dossiê de defesa da candidatura também faz comparação com outras cidades e na analogia feita com Nova York é apontado o diferencial de que ambas podem ser designadas de cidades melting pots, onde a vitalidade da cultura urbana as define. Sobre isso, Peter Hall (1998) escreveu uma extensa obra que destaca a cultura como fator determinante para alcançar novos padrões de civilização nas cidades e - assim como nos critérios estabelecidos pela Unesco para o reconhecimento de um lugar como patrimônio cultural-, considera o impacto das obras de gênios criativos como as bases de um ambiente cultural excepcional em uma determinada época e cidade e que as tornam gloriosa e influente. Os tempos de funcionamento do Cassino da Urca entre 1930 e meados de 40 eram tempos entre guerras e, portanto, afeitos a escapes em ilusões e a sede de criação de novas realidades. A partir da visão de Huizinga (2014) o jogo não é vida real e tem como condição ser um intervalo no dia a dia. Essa característica vinda do universo do jogo de azar parece se expandir para todo o ambiente do Cassino e permitir à criação de atividades inusitadas no Grill Room com uma prática de experimentação rara em ambientes institucionalizados de entretenimento. No Cassino da Urca criou-se um cenário para que a provocação à fantasia a ser oferecida ao público não tivesse limites. $\mathrm{Na}$ cenografia, na programação artística e cultural, na comunicação, no envolvimento com causas sociais ou na aproximação da agenda de desenvolvimento da indústria, comércio, governos, cidades ou mesmo países; criou-se no lugar, e em torno dele, uma aura de superação da realidade com uma proposta de novas tendências que marca sua atuação como um lugar da cidade movido pelas novidades. No Cassino aconteceu um raro senso de oportunidade criativa e com os espetáculos se via o encontro de tudo que a emergente indústria cultural vinha promovendo em todos daqueles anos por meio do teatro, rádio, discos, bailes e festas, do cinema e das revistas e jornais numa nova forma de promover divertimento. A diversidade das atrações confere ao lugar um perfil de frequência eclética onde muitos artistas brasileiros iniciaram suas atividades, ao lado de grandes nomes internacionais, e fizeram sua fama e carreiras despontar. Dalva de Oliveira, Herivelto Martins, Linda \& Dircinha Batista, Emilinha Borba, Dick Farney, Marlene, Virgínia Lane, Lourdinha Bittencourt, Grande Otelo e muitos outros além de Carmen Miranda ao lado de astros de outros países como Bing Crosby, Josephine Baker, Virgínia Lane, Lucienne Boyer e Pedro Vargas, fizeram do Cassino da Urca uma emblemática casa de espetáculos do Rio de Janeiro e da América Latina. 


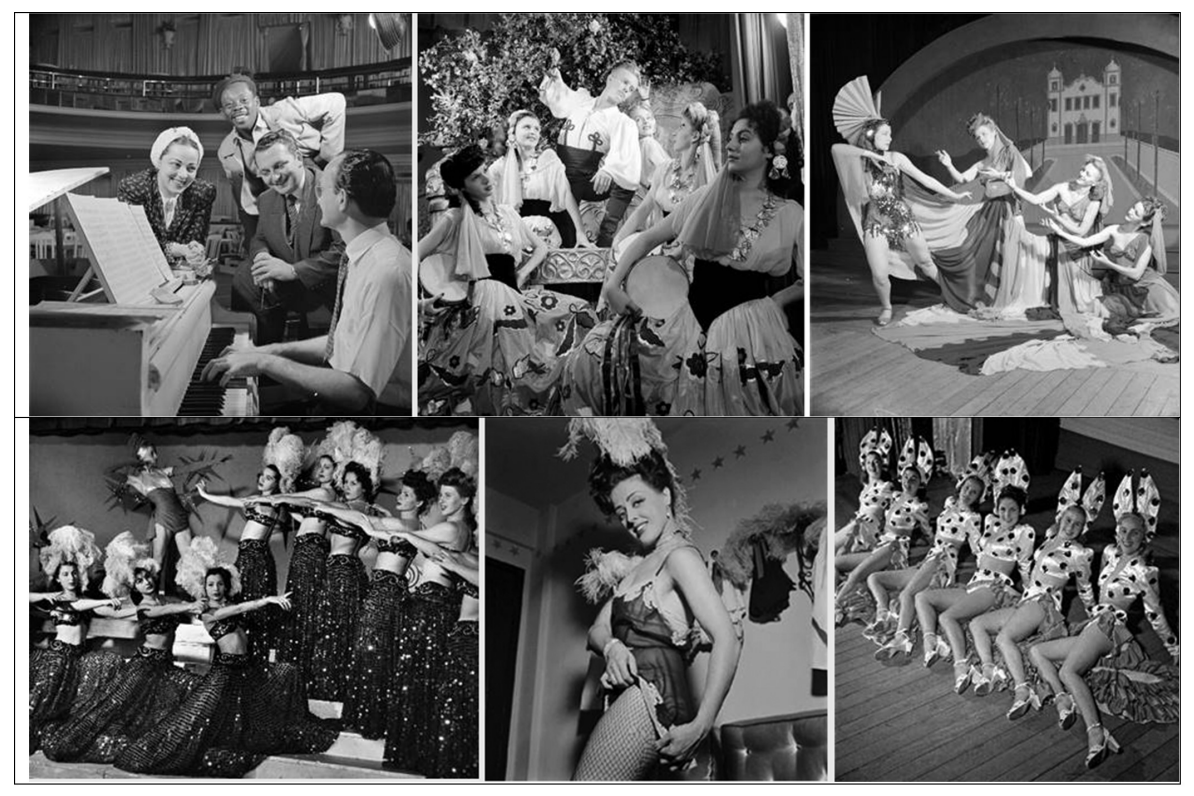

FIGURA 3.

Painel de talentos e atrações.

Fonte: Carlos Moskovics/Acervo Instituto Moreira Salles. Linda Batista, Grande Otelo, Herivelto Martins e Ary Barroso, ao piano, década 1940, Shows no Cassino da Urca e Coristas 1940, 1941; José Medeiros/ Acervo Instituto Moreira Salles. Virginia Lane. Rio de Janeiro

O Cassino da Urca se tornou o mais popular da cidade. O lugar era palco de grande pluralidade (Castro, 2005) onde os trabalhadores, intelectuais e artistas da Lapa e de outros bairros da cidade se misturavam com os políticos, empresários e as famílias da sociedade entre os turistas nacionais e internacionais. Essa presença plural de públicos tinha no jogo e na programação, os motivos de atração.

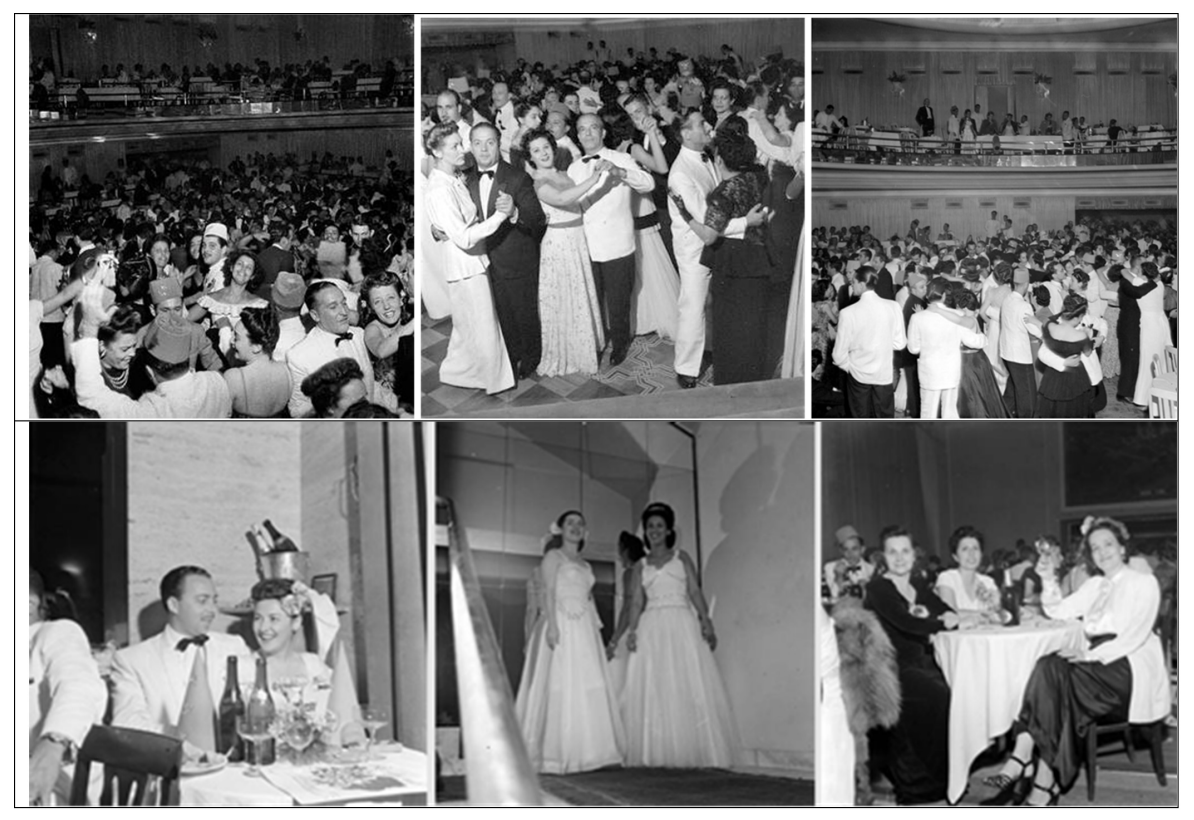

FIGURA 4.

Painel de iniciativas, comemorações e públicos.

Fonte: Carlos Moskovics/Acervo Instituto Moreira Salles. Baile Cassino da Urca década de 1940. Rio de Janeiro. 
O lugar se tornou um autêntico ponto de apostas criativas de muitos profissionais de talento e por meio de alguns deles pretendemos compreender como naquele sítio se formou o fértil ambiente de inovação que refletiu o espírito do tempo, Zeitgeist ${ }^{[2]}$, da entrada da modernidade e na construção da paisagem cultural do Rio de Janeiro.

\section{A aposta e o protagonismo Situado}

Voltando as ideias do escritor holandês Johan Huizinga que em 1938 apresentava no livro Homo Ludens um estudo sobre o jogo como fenômeno cultural, discutindo o seu papel como nuclear na formação da cultura humana, podemos olhar como fenômeno cultural o que ocorreu no mesmo período no Cassino da Urca. No livro, sua abordagem é baseada na ideia de que o jogo:

Ultrapassa os limites da atividade puramente física ou biológica. É uma função significante, isto é, encerra um determinado sentido. No jogo existe alguma coisa "em jogo" que transcende as necessidades imediatas da vida e confere um sentido à ação. Todo jogo significa alguma coisa [...] seja qual for a maneira como o considerem, o simples fato de o jogo encerrar um sentido implica a presença de um elemento não material em sua própria essência. (Huizinga, 2014, pp. 2-3).

Dessa maneira, a função significante da aposta, para além do jogo em si, pode ser vista como uma atitude que permeia o comportamento dos que faziam acontecer o universo pulsante do Grill Room do Cassino. A hipótese é que a configuração desses comportamentos revele o diferencial do Cassino da Urca e a aposta possa ser percebida como uma atitude presente e necessária diante do enfrentamento de situações concretas, determinadas e de risco com o território e seu emaranhado de agentes. Por meio da aposta percebe-se que ali ocorria uma práxis organizacional espontânea, complexa e experimental. De acordo com Hassan Zaoual (2006), economista e escritor que questiona os pressupostos do modelo único do desenvolvimento econômico e que nos leva ao pensamento pós-global do protagonismo situado, as práticas informais nos países do Sul apresentam universos complexos se observados os modos de funcionamento social dos empreendedores locais. Ele alerta que seus comportamentos só são compreensíveis a partir de um conhecimento acerca do seu sítio de pertencimento e que mesmo quando eles dirigem atividades mercantis, fazem isso inscritos em um imaginário local onde a mestiçagem e a complexidade do social e cultural são preponderantes nas tomadas de decisão.

As apostas são enfrentadas dia a dia pelos protagonistas por meio de um enraizamento na própria situação do sítio. Nesse sentido, as apostas feitas pelos empreendedores são baseadas em aspectos da vida concreta e resultam, portanto, de um protagonismo situado. É nessa perspectiva, aliada as já citadas ideias de Hall (1998), naquilo que confere a um tempo e lugar a marca da ação de gênios criadores, que apresento nesse estudo exemplos do que proponho chamar de protagonismo situado de cinco líderes carismáticos que fizeram suas escolhas e apostaram no Cassino da Urca, definindo-o com seus protagonismos. Por serem dotados de carisma e atitude empreendedora em diferentes campos de atuação, cada um deles trouxe uma colaboração ímpar na trajetória do Cassino. Suas performances se entrelaçam e se misturam fornecendo um campo de investigação sobre um novo modo e uma nova forma de promover entretenimento e convivência social à época. Gimenez (2016, p.372) afirma que "é da percepção de quem empreende sobre o espaço de atuação que surge a interpretação de qual é a situação, e a partir dessa interpretação é que serão tomadas decisões”. Já Lomnitz (2009, p. 18), ao abordar redes sociais, cultura e poder contextualiza que "cada pessoa é o centro de uma rede de solidariedade e, ao mesmo tempo, é parte de outras redes e que solidariedade implica em um sistema de intercâmbio de bens, serviços e informação que ocorre dentro da sociabilidade mediante um sistema de reciprocidade". Assim, as decisões e a sociabilidade desse grupo de empreendedores criativos podem espelhar o que ocorreu no Cassino da Urca. Na sequência apresento algumas passagens das trajetórias do proprietário e administrador Joaquim Rolla, do cenógrafo e diretor artístico Luiz de Barros, da artista Carmem Miranda, do relações públicas e produtor artístico Carlos Machado e da primeira dama do país 
Darcy Vargas. Suas ações no Grill Room do Cassino da Urca são narradas por meio de episódios que configuram não só suas apostas, mas também a constituição do próprio lugar como um agente cultural carioca do seu tempo.

\subsection{Joaquim Rolla: o rei da aposta}

Joaquim Rolla, um carismático mineiro tornou-se um dos mais conhecidos empreendedores do entretenimento do país. Sua trajetória de ousadia, participação e transformação marca a história cultural da cidade do Rio de Janeiro. JR vinha de erros e acertos em Minas e perseguido por ligaçóes políticas toma o Rio de Janeiro como destino. Com o jogo de azar já legalizado em 1933, JR se viu diante de uma jogada de alto valor e risco e acabou ganhando para seu ex-sócio dos tempos de negócios em Minas que não tendo como lhe pagar ofereceu uma cota na sua empresa, o Cassino da Urca. (Perdigão \& Corradi, 2012). Seu envolvimento no novo negócio ganho no jogo foi imediato e o ímpeto de melhorá-lo também. JR passou a conhecer o funcionamento do lugar e sua dedicação e proximidade com os funcionários o tornou um sócio essencial no dia a dia da operação, passou a frequentar o lugar e a praia do Cassino, se tornou amigo de moradores e negociantes do bairro da Urca e começou a fazer do lugar um ponto de encontro de políticos e amantes dos clubes de futebol. Liderou as reformas para transformar e o lugar numa casa de jogo e entretenimento a altura das suas ambições e profissionalizou a área artística e a operação pela lei que orientava as casas de jogo. Em seguida, JR compra a Companhia proprietária do imóvel e na renovação do contrato com a arrendatária (da qual ele já detinha $50 \%$ das ações) os sócios lhe vendem o restante das ações. Como aprendiz de dono do cassino resolveu implantá-lo reunindo aos poucos um time de profissionais e personalidades dos mais variados campos para enfrentar o novo e desconhecido negócio.

JR apostou no Grill Room como o alvo das mudanças transformado o lugar num ambiente cinematográfico com várias orquestras de música erudita, jazz e tangos argentinos, atrações estrangeiras e numerosos bailes, atraindo também ao cassino a elite carioca (Perdigão \& Corradi, 2012). Se por um lado os investimentos e o profissionalismo artístico tomaram conta da estrutura cenográfica e da programação do lugar, JR passa a atuar fortemente por meio da comunicação e cria a A.D.A Agência de difusão de Anúncios, exclusiva do Cassino com a função de difundir as atrações e os serviços do cassino, promover o merchandising de produtos e serviços do comércio nas instalações e nos programas do Grill-Room, fechar os eventos e celebrações vinda da sociedade e promover ações turísticas. Em 1936, JR faz sua primeira parceria com a Rádio Record e em seguida com Assis Chateaubriand faz um contrato não só de exclusividade com a Rádio Tupi como também de parceria na contratação das atrações estrangeiras que cantavam na rádio de dia e no Cassino à noite. (Perdigão \& Corradi, 2012) No final desse ano, JR aposta no que viria ser uma das mais relevantes atrações do Cassino da Urca ao contratar Carmem Miranda para cantar numa noite quando o cassino recebe o presidente dos Estados Unidos, Franklin Roosevelt. JR contrata Carmem Miranda, -que já era uma artista de sucessocomo artista exclusiva e tanto o cassino como a cantora se consagram mundialmente.

O Cassino da Urca foi responsável pelo lançamento de grandes obras de sucesso musical de compositores, cantores e orquestras que marcaram sua época e se tornaram verdadeiros ícones do imaginário brasileiro até os dias atuais. As obras são resultado dos encontros criativos de um lugar onde as parcerias e experimentações eram desenvolvidas entre os artistas num ambiente de diversidade promovido pela aposta na experimentação de JR. A articulação de JR na gestão do Cassino da Urca revela que seu espírito empreendedor carismático ativou os negócios entre o Cassino e as rádios, gravadoras, teatros, cinema, os artistas, técnicos e agentes criativos tanto como contratante e como patrocinador com recursos financeiros, apoio técnico e artístico além de divulgar e exibir os talentos nos seus Cassinos da Urca, Icaraí e Araxá. Conectado aos temas e causas do momento, JR não deixava passar a presença do Cassino como agente parceiro da indústria cultural, dos setores produtivos e políticos da sociedade e assim o sentido de pertencimento do próprio Cassino se ampliava por toda cidade. As duas grandes paixões dos brasileiros; o carnaval e o futebol eram alvo de permanente 
envolvimento do Cassino da Urca. O que se destaca na relação do Cassino da Urca com a municipalidade e as entidades carnavalescas do samba é a sua presença na organização das atividades e como patrocinador integrando as atrações do próprio Cassino na promoção do carnaval de rua. Ao lado do Departamento de Turismo da Cidade e da União das Escolas de Samba JR atua como grande parceiro do concurso de marchas e sambas com desfile na Rio Branco (que se tornou tradição no carnaval da cidade) no carnaval 1938. No futebol o Cassino patrocinou campeonatos e a transmissão nas rádios com narrações feitas por locutores famosos e foi patrocinador exclusivo da Copa do Mundo de 1938, a primeira a ser transmitida ao vivo no Brasil. (Perdigão \& Corradi, 2012).

Ao longo dos anos, os planos de JR se ampliaram com a construção do Hotel e Cassino Quitandinha em Petrópolis, mas com a lei que proibiria o jogo no país (decreto do presidente Gaspar Dutra em 1946), ele fecha o Cassino da Urca e vende o prédio para Assis Chateaubriand. JR morreu aos 72 anos deixando a marca de um empreendedor brasileiro que fazia do Cassino um lugar que promovia a potência das circunstâncias e capacidades da cidade.

\subsection{Luiz de Barros: a magia cinematográfica no Grill da Urca}

Carioca do bairro do Catete, Luiz de Barros relata no livro "Minhas Memórias de Cineasta" editado em 1987, que seus estudos no Teatro Municipal do Rio e em Milão com mestres da cenografia foram a base de sua formação. Em Paris, LB começa a fazer cinema na Garamond mas volta ao Brasil com o início da guerra em 1914, começa no cinema como ator, produtor e empreendedor e em 1916 já experimenta um grande sucesso. Considerado um dos mais fecundos e singulares cineastas da cinematografia brasileira pelos críticos do cinema como Álvaro Pacheco, sua produção de filmes de longa metragem ultrapassa os cem títulos e de curta metragem vai mais além. (Barros, 1978). LB também inovou com sua companhia de teatro apresentando o teatro de revista com cenários luxuosos e muitas coristas, estilo considerado pelos escritores e jornalistas como um trabalho de crítica social, de costumes e irreverente. (Petrucci, 2005) Com o convite de JR para que ele assumisse a direção artística da casa em 1933, sua múltipla capacidade criativa transforma o lugar num ambiente de sonho, que em muito contribuiu para marcar o diferencial do entretenimento no Cassino da Urca desde o seu início. Foi sua a aposta na criação de cenários cinematográficos e inéditos de extrema beleza, em diversificar as orquestras e trazer atrações internacionais, por meio de suas relações internacionais. Seu talento de cineasta e cenógrafo tinha como meta levar luxo ao lugar e atrair a elite que ainda era refratária a frequentar a Urca. LB arrebata para o lugar a admiração e o prestígio da noite carioca que lhe garantiam o espaço profissional de comando da programação para um público dos mais diversos gostos, uma marca característica do lugar. A estratégia completava-se com a atitude de JR de exímio aglutinador de interesses e sua obstinação em tornar o lugar o melhor Cassino da América Latina. Com a inauguração do Cassino Atlântico, Luiz de Barros saiu da Urca e dedicou-se a casa concorrente e em 1936 volta para participar da grande reforma em que JR investe para alavancar a liderança de volta ao Cassino da Urca.

$\mathrm{Na}$ Urca, Barros inspirado pelas maiores casa de show que conhecera num grad tour pela Europa no princípio do século, conheceu um sistema de palcos inédito. Remodelou o espaço interno do grill-room, colando dois palcos um no outro, mas com mobilidade para que fossem utilizados independentemente. [...] um deles tinha um elevador que transportava os artistas num alçapão num andar inferior, e o outro tinha mobilidade para alavancar ou recuar sobre a parte da pista de dança[...]. Este palco marcou época na história do show business, inserindo o Rio de Janeiro no cenário internacional do turismo de luxo." (Perdigão \& Corradi, 2012, pp. 185-186).

LB deixa no Cassino sua marca de inventividade e pluralidade de talento com a magia de realizar e promover sonhos e marca época na história do cinema brasileiro com "sua formação artística de belas artes, um eficiente e originalíssimo cenógrafo, um cenarista exímio e um cenotécnico de incalculáveis recursos" (Modesto, 1978, p. 16). 


\subsection{Carmem Miranda: a pequena notável do Cassino, do Brasil e do mundo}

Foi pelas mãos do músico baiano Josué de Barros que a jovem Carmem Miranda nascida portuguesa e filha da Lapa carioca participou do festival do Instituto Nacional da Música em 1929 para sua primeira plateia. Sob a direção artística de Pixinguinha, em 1930, ela grava vários sambas canção no selo da Victor e já se consagra no carnaval com a célebre marchinha "Taí" de Joubert de Carvalho e "Iaiá Ioiô" de Josué de Barros. Ao fim do mesmo ano CM já havia gravado 40 músicas, atendido convites para se apresentar em Buenos Aires, era chamada de rainha do disco pelos jornais e em seguida se tornado a garota propaganda da marca Leite de Rosas. Ruy Castro no livro que traça sua biografia, destaca que CM "aos olhos e ouvidos do público, era a primeira mulher brasileira a criar para si uma personalidade pública, e viver dela”. (Castro, 2005, p.92). A época de ouro da música brasileira começa a ser marcada a partir de 1932 no rádio, no disco, no teatro, no cinema, os direitos autorais profissionalizam a nova indústria e CM ocupa todos os campos de atuação para uma artista naquele momento da capital federal. CM era participante da vida da cidade, subia o morro para rodas de samba, participava de comissões julgadoras, festas e circulava livremente nos mais variados ambientes da sociedade. O perfil extravagante das suas vestimentas com turbante e um salto de plataforma de madeira altíssimo marcam definitivamente seu estilo brejeiro e inconfundível de adereços que representam as frutas, os balangandãs e o colorido brasileiro. Sob a diretoria artística de Cesar Ladeira na Rádio a Mayrink Veiga, CM recebe o apelido que se tornou sua marca; “A pequena notável”. Já em 1936, uma nova oportunidade entrou na vida de Carmem Miranda e com ela sua consagração; os cassinos, em especial o Cassino da Urca. CM é contratada como cantora exclusiva para o Cassino da Urca e para conseguir de Joaquim Rolla o cachê que queria, ela aposta;

Eu vou cantar aqui duas vezes por noite e não vou repetir nem um vestido durante um mês. As mulheres virão me ver, por causa dos vestidos, e trarão os homens que virão jogar. (Castro, 2005, p. 140).

Seu sucesso imediato no Cassino atraiu também Assis Chateaubriand, dono do "Diários e Associados", grande homem da mídia e parceiro de JR que a convida para o casting da Rádio Tupi que inaugurava no Rio em 1936. Carmem passa a ser a grande atração do Cassino ao lado do Bando da Lua, além de cantar duas vezes por noite, ela ainda desenvolvia uma relação de amizade com os frequentadores e frequentadoras indo às mesas depois dos shows e participando à tarde de ações beneficentes como novos fã̃s, jovens que não podiam frequentar à noite. A Urca já se tornara um bairro especial com a agitada vida noturna do Cassino e um sossegado lugar de dia para se morar e foi lá que Carmem Miranda comprou uma casa ao lado da moradia de colegas, artistas, cenógrafos, costureiras, pintores, coreógrafos, bailarinas e técnicos. Foi no palco do Cassino da Urca que Carmem Miranda fez explodir toda sua experiência e potência criativa em meio a muitos talentos, experimentação de saberes e diversidade de gêneros artísticos. Um novo código cultural se forjava e representava com força o caráter brasileiro de ser em que a grande maioria das pessoas se via. A celebração dos talentos tinha também o reconhecimento do mercado do entretenimento internacional. Naquela época os Estados Unidos vivam seu período fértil de produção da música popular com a força da indústria da Broadway, Hollywood, New Orleans e o Harlem na promoção de talentos, canções, agentes e veículos que promoviam mundo afora a cultura americana. Em muitos países essa invasão foi significativa, mas no Brasil ela encontrou limites.

Nesse período, os sambas e as marchinhas sustentavam formidáveis $50 \%$ do mercado. É mais formidável ainda quando se sabe que as três principais gravadoras - Odeon, Victor e Columbia - que operavam no Brasil eram estrangeiras e duas delas americanas. [...] O Brasil respirava nacionalismo, o momento pertencia à música brasileira, e o samba era o ritmo nacional por excelência - produzido por negros, brancos, e encantando homens e mulheres, ricos e pobres, jovens e velhos. (Castro, 2005, p. 159).

Foram essas as circunstâncias em que o empresário americano Lee Sheubert, dono da maior rede de teatros dos Estados Unidos, assistiu Carmem Miranda no palco da Urca e com a aceitação e o apoio de JR, ela 
segue contratada com o Bando da Lua para os Estados Unidos em 1939. Lá ela se torna a famosa The Brasilian Bomb Shell (sic) com sucesso imediato na Broadway e na sequência, contratada pela Fox Filmes, se torna internacionalmente famosa e faz história na indústria de Hollywood. Em 1940 CM, passa uma curta temporada no Brasil e participa a convite de JR de uma noite beneficente no Cassino patrocinada pela primeira dama, Darcy Vargas. Indicada para interpretar canções latino-americanas ela é recebida com frieza por uma plateia politizada (Estado Novo) e reativa aos Estados Unidos. A reação de Carmem Miranda foi rápida e em duas semanas com o apoio dos músicos, maestro, cenógrafo e do próprio JR, ela dá a volta por cima e estreia no Cassino uma temporada de retumbante sucesso com o sambas "Disseram que voltei americanizada", "Ela disse que tem!", "Voltei pro morro" entre outros dos seus hits de sucesso. Residente em Los Angeles, no dia 5 de agosto de 1955, CM morre aos quarenta e seis anos de idade e dela fica o símbolo artístico personificado do Cassino da Urca e do espírito desse tempo que legitimou o Brasil como uma potência de caráter próprio e valor cultural.

\subsection{Carlos Machado: o Cassino como reino carioca}

Nascido na cidade de Porto Alegre e da família do célebre Júlio de Castilhos, Carlos Machado teve formação católica de orientação alemã e em 1922 se muda com a família para o Rio de Janeiro. Morou em Paris por um longo período, se aprofundou nos estudos do que era moda na música e nos espetáculos teatrais e trabalhou no Cassino de Paris como dançarino e ator na revista do célebre Maurice Chavalier. Como partner e produtor de Mistinguett, a mais famosa estrela do musi-hall francês teve seu nome artístico consolidado em Paris. De volta ao Brasil CM teve início a uma ascendente trajetória no Cassino da Urca pelas mãos do seu conterrâneo o capitão Lulu, então sócio de Joaquim Rolla no Cassino Icaraí. Ao observar que as orquestras de danças que se apresentavam nos cassinos não participavam ativamente do espetáculo CM cria uma nova função para a orquestra que é a de animar os dançarinos e ser uma atração para o público ao gerar interesse visual e se tornar um show à parte. Assim, com músicos de alta qualidade, todos dominando instrumentos de percussão brasileiros e cubanos e com jogos de guarda-roupa para as várias ocasiões, nasceu a orquestra Brasilian Serenate (sic). Sinônimo do Cassino da Urca, quase considerada orquestra oficial do Estado Novo, a Brasilian Serenate que estreou na Urca em junho de 1940 terminou com o fechamento do lugar em 1946 com a publicação do decreto com a proibição do jogo no país. No livro Carlos Machado se refere ao Joaquim Rolla como um patrão amigo e todo poderoso; "um homem que acreditava em seu semelhante, mas que acreditava, acima de tudo, em si próprio. (Machado \& Pinho, 1978, p.115). No registro como funcionário do Cassino ele declara:

Os funcionários e profissionais que trabalhavam no cassino eram da maior categoria. Ganhávamos bem e tínhamos estabilidade. Os artistas e músicos eram contratados pelo prazo de quatro anos. (Machado \& Pinho, 1978, p. 115).

Sua memória sobre o bairro da Urca mostra o olhar do artista que fez parte de uma geração de talentos que reconhecia o pertencimento ao lugar. Sobre a vida na Urca ele diz;

A Urca era um mundo dentro do Rio de Janeiro. Um bairro com vida própria, onde quase todas as pessoas se conheciam e se ajudavam. Em quartos, apartamentos, pensões e casa, moravam as artistas bailarinas, músicos, croupiers, profissionais de todas as classes que trabalhavam no cassino. Frequentavam os mesmos cafés, bares, restaurantes, tomavam banho de mar, tinham crédito nos mercadinhos açougues, armazéns, padarias. Não sei o que o progresso fez com esse bairro tão simpático, mas para mim, continuar sendo sempre a família Urca. (Machado \& Pinho, 1978, p. 115).

Com o título de Rei da Noite dado pelo jornalista Sergio Porto, Carlos Machado fez fortuna nas roletas dos cassinos e fez da noite seu ambiente de realizações com musicais e peças de sucesso que foram exibidos depois nas boas boates do Rio de Janeiro e Nova York na década de 60. 


\subsection{Darcy Vargas: o consentimento público social do Cassino da Urca}

Darcy Vargas, esposa do presidente Getúlio Vargas, é a primeira mulher a ocupar um cargo de direção na política social no Brasil na presidência da Legião Brasileira da Assistência. Desde a sua criação em 1942, Darcy desempenha um papel significativo de participação política atrelado ao social, criando um modelo novo para atuação das primeiras-damas na política brasileira (Simili, 2008). Com uma liderança carismática Darcy mobilizou uma eclética rede de relacionamentos e promoveu inúmeras iniciativas em parceria com Cassino da Urca com festas, jantares dançantes, peças teatrais e desfile de modas etc. A parceria estratégia de mobilização e sensibilização da elite servia ao Cassino que tinha na presença dos abastados da sociedade tanto o prestígio nos eventos e nas mesas de apostas, como o protagonismo em encontros representativos, de onde surgiam e eram anunciados novos negócios e os destinos político do país. Já para a Primeira Dama proporcionava a visibilidade da participação cidadã solidária e servia como arrecadação de recursos financeiros para suas causas beneficentes. O Cassino da Urca foi um instrumento de arrecadação financeira pela alta arrecadação de impostos, que regulamentada pela lei de liberação do jogo, era destinada às ações sociais do governo. Para além da mobilização e frequência de uma elite em torno das ações sociais o espírito humanista atraía todos os públicos aos eventos e dava ao lugar, ao Cassino, um caráter de local de entretenimento, convivência plural e de exaltação do espírito público. As inúmeras iniciativas da primeira dama do país no Cassino da Urca e fora dele, serviam de mote para a criação artística onde pessoas de diferentes classes sociais conviviam durante os processos criativos e no palco. As atividades da LBA (Legião Brasileira de Assistência) e de outras entidades assistenciais no Cassino da Urca estavam sempre ligadas às novas tendências da arte e do entretenimento. (Perdigão \& Corradi, 2012). Um exemplo emblemático dessa parceria foi o caso da revista Joujoux e Balangandans. Liderada por Darcy, e apresentada no Teatro Municipal do Rio de Janeiro, foi totalmente financiada por Joaquim Rolla e reuniu diretores, encenadores, criadores e a orquestra do Cassino da Urca junto a um elenco misto de profissionais e amadores com a participação de pessoas da sociedade. A peça de teatro de revista foi montada duas vezes, mas foi na segunda temporada em 1941 que a revista tomou corpo de uma ópera nacional de sucesso e onde foi lançada a música Aquarela do Brasil, que se torna um hino da música popular do país. Darcy Vargas foi uma liderança na consolidação do Cassino da Urca, o enraizando de suas atitudes de espírito público trouxe um protagonismo inclusivo ao Cassino que contribuiu para transformação social na capital federal.

\section{CONSIDERAÇÕES FINAIS}

Ao olhamos as dinâmicas das apostas na atuação de cada protagonista, de acordo com as situações e suas circunstâncias na construção do Cassino da Urca, podemos fazer algumas sínteses reflexivas de suas contribuições a luz do protagonismo situado proposto por Zaoual (2006). Joaquim Rolla, como o empreendedor proprietário e hábil negociador, que apostou e profissionalizou o entretenimento com uma gestão agregadora relacional, que investiu em pessoas criativas, na comunicação e fez de uma rede de relacionamentos sua estratégia de negócio. Num espaço aberto a prática do relacionar-se, Joaquim Rolla não media esforços para promover encontros, mediar novas propostas, atrair novidades e apostar no novo. Sua visão ampla de que um lugar de convivência cultural deve ultrapassar os limites das relações convencionais mais parece com o entendimento de que relacionar-se é muito mais uma atitude de coragem do que de uma fórmula pronta e intencionada em levar vantagens previsíveis e pontuais dos negócios. Sua atitude em apostar numa racionalidade situada, por si só refratária a um modelo econômico único, demonstra que o compromisso com "as raízes, o pertencimento, à rede, à proximidade, à cooperação, à reciprocidade etc. oferece certezas em maior proporção" (Zaoual, 2006, p.241). Luiz de Barros como artista versátil, cenógrafo, cineasta e visionário diretor artístico ambientou e promoveu o lugar como um universo cinematográfico 
afeito aos sonhos e desejos da época. Ele pôde enfrentar a superação dos limites do fazer de forma concreta atenuando as fronteiras entre os saberes disponíveis na época ao apostar na transdisciplinaridade para suas criações e cenografias. Pode-se concluir também que ele soube "imprimir um conjunto da cosmovisão dos atores da situação com senso prático do seu mundo” (Zaoual, 2006, p.240). Carmem Miranda como a cantora que trouxe ao lugar toda sua trajetória de sucessos (na nova indústria cultural) e encontra a efervescência criativa que a faz tornar-se uma artista celebrada nacional e internacional com a marca de brasilidade que criou junto com o próprio Cassino. Sua popularidade por meio da identificação estética, poética e musical com os códigos de brasilidade impressos a partir do Rio de Janeiro e do Cassino, indicam uma comunicação direta com seu meio com uma "plasticidade que varia em função do tempo, da experiência e dos espaços simbólicos locais" (Zaoual, 2006, p.240). Carlos Machado, que começou no Cassino como aprendiz, virou animador, apresentador e maestro criando uma das mais memoráveis orquestras do lugar. Sua trajetória, "percurso e sistema de crenças em recomposição constante" encontra no Cassino da Urca um sítio de aprendizagem e evolução. Seus depoimentos sobre as relações com o Joaquim Rolla como seu chefe, com seus colegas e com os amigos moradores da Urca nos demonstram o quanto "o sítio tranquiliza e dá confiança à transações inerentes ao funcionamento da vida social como um reservatório de normas evolutivas, estabilizadoras do caos da ordem social" (Zaoual, 2006 p.137-139). E ainda, Darcy Vargas como primeira dama e ativa mobilizadora social que aproveita a nova política pública, - que destina boa parte dos impostos dos cassinos para a área social - e amplifica sua atuação no Cassino da Urca. Darcy aposta na realização de significativas e transformadoras iniciativas que, envolvendo públicos diversos e dedicadas a causa beneficente, acabam criando no lugar um espírito de consentimento social público, um ambiente coletivo sem ser coletivizado. Ou seja, ocorre "a multiplicidade das dimensões da existência humana no sítio como um mecanismo imunitário contra todo determinismo" (Zaoual, 2006, p. 239-240).

Ao final, muitas seriam as possibilidades de identificação das ações desses protagonistas como respostas que não se calariam diante da questão de como o protagonismo situado favorece para que as potencialidades culturais de uma época se efetivem num lugar. O que gostaríamos deixar como reflexão, e que o próprio Zaoual (2006) enfatiza como a natureza possibilista e imprevisível dos sítios, é que com o protagonismo situado há chance de ganho das apostas. Sem ele as chances diminuem. Podemos assim concluir que o Cassino da Urca se caracterizou como um sítio de pertencimento, ao mesmo tempo em que ele também se configurou um protagonista situado da cidade do Rio de Janeiro. Esse protagonismo nos parece exemplar como forma de contribuir para as recentes reflexões e estudos acadêmicos sobre as relações do "homem com o meio, onde modos de vida produzem singularidades relacionais existentes, e definem os traços da própria paisagem" (Ferreira, 2019 p.418) que surgem em torno do reconhecimento do Rio de Janeiro como paisagem cultural patrimônio da humanidade pela UNESCO com o objetivo de despertar para uma construção social que compreende o lugar do patrimônio dentro da cidadania contemporânea (Fonseca, 2017). A história do Cassino da Urca pode ser uma referência para que o jogo da inovação institucional, no espaço da arte e do entretenimento, continue a ser jogado com foco na aposta dos jogadores. Afinal, o que um dia se torna patrimônio pode ter sido, na sua origem, uma aposta que espelhou processos de protagonismo situado na organização da sociedade.

\section{REFERÊNCIAS}

Aizen, Mário. (1990) Urca: construção epermanência de um bairro. Rio de Janeiro: Prefeitura do Rio de Janeiro. Barros, Luiz. (1978) Minhas Memórias de Cineasta. Rio de Janeiro: Editora Arte Nova.

Batista, Helmut. (2002) in: Batista, Eliezer; Silva, Helmut F. B. da Rio de Janeiro 360. Rio de Janeiro: Trezentos Sessenta Graus

Castro, Ruy. (2005) Carmem: uma biografia. São Paulo: Companhia das Letras.

Coelho, Teixeira. (2008) A cultura e seu contrário, São Paulo: Iluminuras. 
Debord, Guy. (2007) A sociedade do espetáculo. Rio de Janeiro: Contra Ponto.

Ferreira, Alda, \& Nóbrega, Cláudia. (2019) Saberes e práticas paisagísticas na construção da paisagem cultural carioca, in: Revista Patrimônio e Memória, v. 15 n. 2. Assis: Universidade Estadual Paulista. http://pem.assis.unesp.br/ index.php/pem/article/view/927

Fonseca, Maria Cecília Londres. (2017) O Patrimônio em processo: trajetória da política federal de preservação no Brasil. Rio de Janeiro: EDUFRJ, 4 ed.

Gimenez, Fernando Antônio Prado. (2016) Empreendedor cultural: uma identidade rejeitada? In: Revista de politica cultural, Salvador, v.9,n.1, p244-267, jan./jun. https://portalseer.ufba.br/index.php/pculturais/article/view/24 410

Hall, Peter. (1998) Cities in Civilization. Culture, Innovation and Urban Order. Reino Unido: Weidenfeld \& Nicholson.

Huizinga, Johan. (2014) Homo Ludens: o jogo como elemento da cultura. São Paulo: Perspectiva.

Instituto do Patrimônio Artístico e Cultural Nacional - IPHAN et al. (2011) Dossiêproposta de candidatura da cidade do Rio de Janeiro a Patrimônio Mundial enviada à UNESCO. Rio de Janeiro.

Kessel, Carlos. (2001) A vitrine e o espelho: o Rio de Janeiro de Carlos Sampaio. Rio de Janeiro: Arquivo Geral da Cidade do Rio de Janeiro.

Lomnitz, Larissa. (2009) Redes sociais, cultura e poder. Rio de Janeiro: E-papers.

Machado, Carlos \& Pinho, Paulo. (1978) Memórias sem maquiagem. São Paulo: Livraria Cultura.

Modesto, Abreu de. (1978) Prefácio. In: Machado, Carlos \& Pinho, Paulo. Memórias sem maquiagem. São Paulo: Livraria Cultura.

Perdigão, João \& Corradi, Euler. (2012) O rei da roleta: a incrível vida de Joaquim Rolla. Rio de Janeiro: Casa da Palavra.

Santucci, Jane. (2005) Os pavilhôes do passeio público: Theatro Casino e Casino Beira. Rio de Janeiro: Casa da Palavra. Simili, Ivana Guilherme. (2008) Mulher e politica: a trajetória da primeira-dama Darcy Vargas 1930-1945. São Paulo: EdUnesp.

Yúdice, George. (2004) A conveniência da cultura: usos da cultura na era global. São Paulo: Humanitas.

Zaoual, Hassan. (2006) Nova economia das iniciativas locais: uma introdução ao pensamento pós-global. São Paulo: DP\&A.

\section{Notas}

[1] ACERVO FUNDAÇÃO BIBLIOTECA NACIONAL. Integram as referências uma seleção de matérias, notícias, reportagens, notas e anúncio sobre o Cassino da Urca e os personagens elencados, identificadas no período entre 1930 a 1946 em periódicos como: Revista O Cruzeiro e nos jornais; A Noite, O Jorna, A Manhã, Gazeta de Notícias, Jornal do Brasil e O Imparcial.

[2] Termo de origem alemã, "Zeit" (tempo) e "Geist" (espírito) que trata da habilidade e da capacidade de algumas pessoas, movimentos coletivos ou instituições para captar e refletir de forma acurada os elementos, crenças, valores e atitudes que caracterizam o "espírito do tempo" em que vivem.

* O presente trabalho foi realizado com apoio do CNPq, Conselho Nacional de Desenvolvimento Científico e Tecnológico - Brasil. 